\title{
Identifying "ownership" through role descriptions to support implementing universal colorectal cancer tumor screening for Lynch syndrome
}

\author{
Kathleen M. West, MS ${ }^{1}$, Wylie Burke, MD, $\mathrm{PhD}^{2}$ and Diane M. Korngiebel, DPhil ${ }^{3}$
}

Purpose: Lynch syndrome cases are underidentified, and universal colorectal cancer tumor screening for Lynch syndrome (UTS) has been recommended. UTS implementation is challenging and few successful examples exist to date, and colorectal cancer patients and at-risk family members exhibit low uptake of genetic services. This study sought to identify the elements that could guide the choice of specialties to implement UTS through three main stages: initiating the screen, returning positive screen results, and providing follow-up.

Methods: To understand stakeholder views on the UTS process, 20 semistructured interviews were conducted with clinicians from six medical specialties crucial for implementing UTS. Data were analyzed using directed content analysis and additional thematic analysis across content categories.
Results: Several clinical specialties could fill necessary roles at each of the main stages of UTS implementation. Participants suggested owners based on attributes of specialty roles, clinical settings, and the routes patients take through the system.

Conclusion: UTS is considered possible in a range of health-care settings, with tailoring. Health systems need to choose who best fills the role's needs based on local resources and processes. These results offer implementation guidance based on role needs, not clinical specialty, in resolving the issue of UTS "ownership."

Genet Med advance online publication 4 May 2017

Key Words: hereditary nonpolyposis colorectal cancer; implementation science; Lynch syndrome; precision medicine; universal tumor screening

\section{INTRODUCTION}

Lynch syndrome (LS) is implicated in 2-4\% of colorectal cancer (CRC) cases and is attributed to autosomal dominantly inherited mutations in mismatch repair genes. ${ }^{1}$ LS also increases the risk of cancers such as endometrial, renal, and others. $^{2,3}$ Identification of pathogenic genetic mutations in patients with CRC has implications for treatment and the prevention of other cancers in the proband and their relatives. The sensitivities of screening guidelines (Amsterdam and Bethesda) commonly used for targeted screening remain relatively low and thus, even when guidelines are followed and family history data are sufficient, many LS patients are not identified. ${ }^{4,5}$ To address this problem, universal tumor screening (UTS) for LS has been recommended, ${ }^{3}$ particularly for those diagnosed with CRC aged 70 or younger. ${ }^{6}$ The potential public health benefit has been determined, ${ }^{4,6}$ and increased genetic testing for LS among CRC cases is a public health priority. ${ }^{7}$ Yet despite support for UTS, implementation is uncommon, and LS cases remain underidentified. This lack has been attributed, in part, to barriers in health-care systems' infrastructures, lack of awareness and clarity of screening guidelines, and issues surrounding cost, staffing, specialty "ownership," ${ }^{8}$ and the establishment of site-specific implementation plans. ${ }^{9}$
Our study aimed to inform UTS implementation through examination of the LS screening process at three stages: initiating the screen, returning positive screening results, and following-up after a positive screen. With a host of specialties potentially involved, assigning ownership of the steps in the process is vital, and adaptable to various settings. There is no prior research exploring ownership at each stage of UTS implementation; therefore, this study provides data that can inform the implementation of UTS across a range of clinical settings.

\section{MATERIALS AND METHODS}

\section{Recruitment}

Twenty interviews were conducted with participants representing specialties with a potential role in implementation of CRC UTS: medical geneticists, genetic counselors, pathologists, oncologists, gastroenterologists, and primary care providers. Purposive recruitment was used to facilitate representation of stakeholder specialties and diverse healthcare settings; snowball sampling then ensured inclusion of experts beyond the authors' professional networks. ${ }^{10}$ Participants represent urban and rural settings, in academic medical centers, local clinics, and hospitals, with varying resources and

${ }^{1}$ Department of Bioethics and Humanities, Institute for Public Health Genetics, University of Washington, Seattle, Washington, USA; ${ }^{2}$ Department of Bioethics and Humanities, University of Washington, Seattle, Washington, USA; ${ }^{3}$ Department of Biomedical Informatics and Medical Education, University of Washington School of Medicine, Seattle, Washington, USA. Correspondence: Diane M. Korngiebel (dianemk@uw.edu) 
Table 1 Participant demographics and site characteristics

\begin{tabular}{|c|c|}
\hline \multicolumn{2}{|l|}{ Gender } \\
\hline Male & 11 \\
\hline Female & 9 \\
\hline \multicolumn{2}{|l|}{ Medical specialty } \\
\hline Medical geneticist & 3 \\
\hline Genetic counselor & 4 \\
\hline Pathologist & 3 \\
\hline Oncologist & 3 \\
\hline Gastroenterologist & 2 \\
\hline Primary care provider & 5 \\
\hline \multicolumn{2}{|l|}{ Roles } \\
\hline Directly involved in Lynch syndrome testing & 16 \\
\hline $\begin{array}{l}\text { No direct involvement, but interest and knowledge about } \\
\text { Lynch syndrome }\end{array}$ & 4 \\
\hline \multicolumn{2}{|l|}{ Sites } \\
\hline Academic medical center & 13 \\
\hline Community-based clinic & 7 \\
\hline States represented & 4 \\
\hline Clinics/hospitals/systems represented & 9 \\
\hline
\end{tabular}

diverse experiences with tumor screening. All sites had some access to genetic counseling services, although for some, access meant traveling hundreds of miles and/or a two-month wait. Table 1 summarizes participant demographics and site characteristics.

\section{Data collection}

Interviews were conducted in person $(n=1)$ or by telephone $(n=19)$ from September 2015 through August 2016, using a semistructured interview guide exploring implementation of each of the three main UTS stages. These stages were identified a priori by an advisory board comprising experts in genetics, pathology, and gastroenterology. Table 2 presents tasks completed at each stage, and Table 3 includes sample interview questions. For each stage, participants were asked which specialty would be the most appropriate owner, then asked to respond to a list of specialties by stating their endorsement (or not) of that specialty and rationale. Interviews lasted 30-60 min, were conducted by one interviewer (D.K.), audio-recorded, transcribed, and deidentified. This study was approved by the University of Washington Institutional Review Board and all participants provided informed consent.

\section{Data analysis}

All transcripts were coded in Atlas.ti 7 software, using a code book based on the interview protocol. The code book was complemented by inductive coding as novel ideas were identified. Coded data were analyzed by directed content analysis $^{11}$ sequentially, in which one coder (K.W.) coded all transcripts and a second coder (D.K.) reviewed and clarified all coding. Both coders performed thematic analysis to
Table 2 Primary tasks associated with each stage of LS CRC tumor screening

\begin{tabular}{ll} 
Stage & Key tasks \\
\hline $\begin{array}{l}\text { Initiate tumor } \\
\text { screen }\end{array}$ & Tumor tissue is excised via colonoscopy or surgery \\
& $\begin{array}{l}\text { Tissue to pathologist for CRC diagnosis } \\
\text { Identify patients with positive CRC diagnosis to } \\
\text { screen } \\
\text { Send tissue for LS screening } \\
\text { LS screening by immunohistochemistry staining } \\
\text { and/or microsatellite instability testing }\end{array}$ \\
\hline $\begin{array}{l}\text { Return positive } \\
\text { results }\end{array}$ & $\begin{array}{l}\text { Receive positive screen results } \\
\text { Identify patient information needs } \\
\text { Convey the accurately interpreted result to } \\
\text { patient } \\
\text { Provide education and recommendations for } \\
\text { confirmatory testing }\end{array}$ \\
\hline Patient follow-up & $\begin{array}{l}\text { Confirm/ensure positive screens receive definitive } \\
\text { genetic testing } \\
\text { Potentially assist patients in identifying and } \\
\text { reaching out to at-risk family members }\end{array}$ \\
\hline
\end{tabular}

CRC, colorectal cancer; LS, Lynch syndrome.

capture themes across coding categories and discordant interpretation was resolved via consensus. ${ }^{12}$

\section{RESULTS}

While health-care organizations often have potential mechanisms for LS screening, such as provider review of family health history, the appropriate specialty to own each stage of UTS is not straightforward. Identifying appropriate specialties depends on necessary attributes of the provider roles, varying needs of specific settings, and the series of providers that patients see throughout CRC diagnosis and treatment. Although all acknowledged the need for multiple providers (team-based or ad hoc), the composition of each team will vary for health systems as well as for individual patients. Thus, we report the range of providers participants suggested could be appropriate to own each UTS stage. Table 4 summarizes these results, which are detailed in the text below.

\section{Stage 1: initiating the screen}

This first stage of UTS involves ensuring that all CRC tumors undergo screening for LS. Participants often described the screen initiation role as requiring direct contact with the tumor or patient, and suggested several possible owners: pathologists first, since they handle all tumors, and gastroenterologists or oncologists for leading colorectal oncology care.

\section{Pathologists}

Because pathologists directly test tumors for cancer, they were mentioned several times as being well positioned to initiate UTS. 
Table 3 Sample interview questions

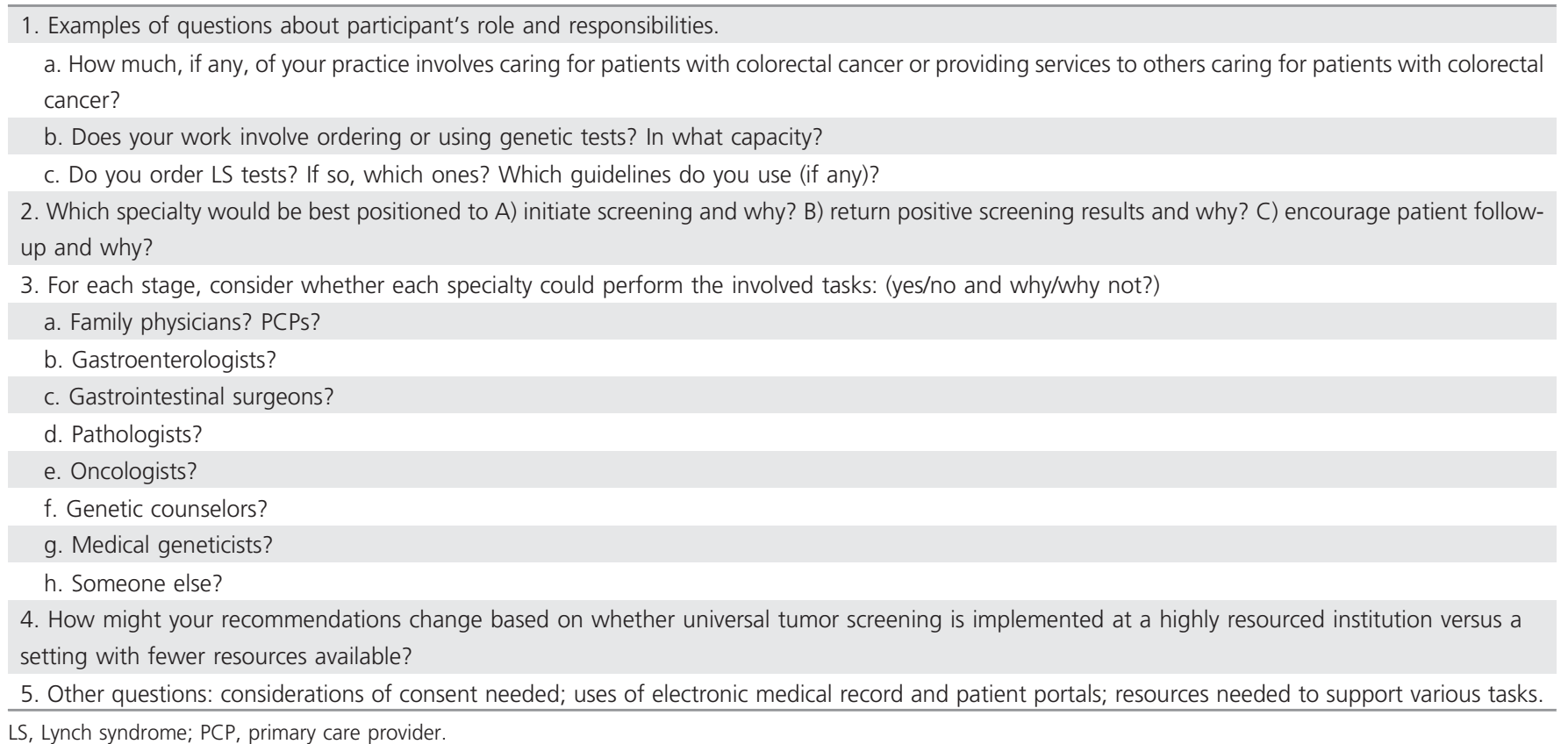

$L S$, Lynch syndrome; PCP, primary care provider.

"The pathologist...because they're the one who are actually doing the analysis of the tumor itself...They don't need to follow up, but...need to initiate the process." (P2, genetic counselor)

"The focal point of our successful screening programs has been anatomic pathology. They hold the tumor in their hands... That's really the control point." (P14, clinical geneticist)

For many participants, pathologists were considered a potential failsafe similar to reflexive testing for breast cancer.

"Could you just have an automatic reflex order that said, "If this was colorectal cancer then run this test?"...Then you wouldn't have to train all the GI docs and surgeons." (P10, primary care provider)

"Every breast cancer specimen gets ER, PR, and HER2 testing...This is breast cancer. These are your three tests you need. To me it should be: Boom. This is colon cancer. These are the tests you need...It should just be built into a pathway." (P13, gastrointestinal oncologist)

Pathologists emphasized that institutional mandates would be necessary for pathologists to screen all positive CRC tumors reflexively for LS:

"If pathology is just ordering Lynch syndrome screening on every single colon cancer that comes across, then that's the strongest, because...then 10 out of 10 , it will happen. The problem with that...is the issue of...self-referral. There are rules about that." (P7, pathologist)

\begin{abstract}
"Because of STARK laws, they [pathologists] are not supposed to be ordering pathology tests...To avoid conflict of interest, the pathologist would need an institutional mandate to screen all." (P18, pathologist)
\end{abstract}

\section{Oncologists or gastrointestinal specialists}

Providers caring for the patient directly could initiate screening, whether oncologists or gastrointestinal specialists (e.g., gastroenterologists or gastrointestinal surgeons). For some early stage CRCs, the only providers would be gastrointestinal specialists, but for patients who see oncologists, initiating an LS screen could be part of routine oncology care.

"I've seen programs where it's...the gastroenterologist who was championing it [UTS]. It could be oncology...The more people clinically want this information the easier it is to implement...." (P11, genetic counselor)

"Oncologists tend to direct cancer care for patients...If someone's going to make a decision on tumor testing, it'll most likely be the oncologists." (P3, primary care provider)

"Medical oncologists may not be the best people because we don't see every patient. For patients with Stage I and, for some cases, Stage II disease, they often don't need chemotherapy after their cancer has been removed surgically." (P15, medical oncologist)

In all cases, the institution or provider group must decide how their team handles initiation, to ensure no tumors are missed. 
Table 4 Summary of ownership results for each stage of UTS implementation

\begin{tabular}{|c|c|c|c|}
\hline Stage & Role attributes needed & Specialties & Attributes of the role, including pros and cons \\
\hline \multirow[t]{5}{*}{$\begin{array}{l}\text { Initiating the } \\
\text { screen }\end{array}$} & $\begin{array}{l}\text { 1. Direct contact with tumor, or sees } \\
\text { patient at time of } C R C \text { diagnosis }\end{array}$ & Pathologists & $\begin{array}{l}\text { Pros: Physically handle tumor } \\
\text { Interact with every case, regardless of patient pathway }\end{array}$ \\
\hline & 2. Able to provide assurance that & & Could perform reflexive testing on all positive CRC \\
\hline & all tumors are screened & & Cons: Require institutional mandate to avoid self-referral \\
\hline & & $\begin{array}{l}\text { Gl specialists } \\
\text { (surgeons, } \\
\text { gastroenterologists) }\end{array}$ & $\begin{array}{l}\text { Pros: Direct contact with tumors through excision or biopsy; Already order } \\
\text { CRC testing on tissues } \\
\text { Could include LS screening order on positive CRCs } \\
\text { Cons: Do not see all cases }\end{array}$ \\
\hline & & Oncologists & $\begin{array}{l}\text { Pros: Could provide failsafe for those patients they see; verify screening was } \\
\text { complete } \\
\text { Cons: Do not see all cases }\end{array}$ \\
\hline \multirow[t]{4}{*}{$\begin{array}{l}\text { Returning } \\
\text { positive } \\
\text { screen results }\end{array}$} & $\begin{array}{l}\text { 1. Provider who orders test is } \\
\text { responsible for returning results } \\
\text { (by self or referral) }\end{array}$ & $\begin{array}{l}\text { Genetic counselors/ } \\
\text { medical geneticists }\end{array}$ & $\begin{array}{l}\text { Pros: Most knowledgeable; equipped to return results accurately and } \\
\text { appropriately for the patient }\end{array}$ \\
\hline & $\begin{array}{l}\text { 3. Has knowledge about complex } \\
\text { genetic screening results }\end{array}$ & & \\
\hline & $\begin{array}{l}\text { 4. Institutional mandates for } \\
\text { reflexive UTS should specify } \\
\text { ownership of results return }\end{array}$ & Oncologists & $\begin{array}{l}\text { Pros: Existing relationship with patient; results may inform care; likely to be } \\
\text { knowledgeable about LS } \\
\text { Cons: Do not see all early stage CRC patients; may not be comfortable } \\
\text { interpreting complex genetic results }\end{array}$ \\
\hline & & $\begin{array}{l}\text { Gl specialists: } \\
\text { (surgeons, } \\
\text { gastroenterologists) }\end{array}$ & $\begin{array}{l}\text { Pros: Takes tumor sample; orders CRC test; may be heavily involved in } \\
\text { care for early stage cancers; likely to be knowledgeable about LS } \\
\text { Cons: May not have detailed enough knowledge about LS to be } \\
\text { comfortable interpreting complex results }\end{array}$ \\
\hline $\begin{array}{l}\text { Patient and } \\
\text { family follow- } \\
\text { up }\end{array}$ & & $\begin{array}{l}\text { Primary care } \\
\text { providers }\end{array}$ & $\begin{array}{l}\text { Pros: Can ensure testing for patients without long-term cancer treatment, } \\
\text { or who have completed treatment but did not have confirmatory genetic } \\
\text { testing; well positioned to support family outreach in absence of genetic } \\
\text { counselors or if PCP treats the whole family } \\
\text { Cons: May not be knowledgeable about LS }\end{array}$ \\
\hline
\end{tabular}

CRC, colorectal cancer; GI, gastrointestinal; LS, Lynch syndrome; PCP, primary care provider; UTS, universal tumor screening.

"I think the biggest thing is to have an agreement among the group on who to do [initiation]." (P5, primary care provider)

\section{Stage 2: returning positive screening results}

The returning results stage begins with a positive LS screening result that must be communicated to the patient, with adequate context to meet the patient's informational needs and recommendations for further testing. Standard practice situates responsibility for returning results with the ordering clinician. However, contemplating ownership of returning results prompted a nuanced discussion, taking into account which provider initiates testing and the complexity of the process. Because the appropriate ordering clinician is not obvious, and might include a pathologist following an institutional mandate, an institution's protocol might also need to specify which provider receives and returns results.

"If the pathologist is ordering it, the pathologist isn't going to call the patient. That's where you can't really rely on your inherent system.” (P12, genetic counselor) 


\section{Genetic counselors or medical geneticists}

Only about one in five positive LS screens-microsatellite instability-high or abnormal immunohistochemistry-results in an LS diagnosis, ${ }^{13}$ indicating that confirmatory genetic testing is needed (unless they have been differentiated, using $B R A F$ reflex testing, as a case of hypermethylation). ${ }^{14}$ Therefore, most respondents thought that the individual returning results must have the in-depth knowledge of genetic specialists. However, genetic specialists generally have no preexisting relationship with the patient and require referrals from the provider directing care.

"Genetics [specialists] will give the absolute correct answer...but the oncologists...They're fine because we have to have them order the test or order the referral to genetics anyway...We do worry a little bit about oncologists that say it [a positive screen] means you have Lynch syndrome because it doesn't. It's a screening test that we have to confirm." (P11, genetic counselor)

In addition, referrals to genetic services in lower-resourced settings may not be simple or even possible.

"Even medical oncologists in the community get confused about how to interpret these results...Even some of my GI partners have difficulty with it sometimes. Your medical geneticist and genetic counselor...not every patient's going to see them...from a resource standpoint." (P19, medical oncologist)

\section{Oncologists or gastrointestinal specialists}

Participants generally agreed that the doctor/patient relationship was important for returning screening results and suggested oncologists or gastrointestinal specialists might fill that role. For more advanced cases, oncologists are heavily involved in patient care, and many are sufficiently familiar with heritable cancer to return screening results.

"I think medical oncologist would be next because obviously we see a lot of it and we are kind of comfortable discussing it...surgeons get the gist of the situation but most of them are not that comfortable with the details." (P15, medical oncologist)

Gastrointestinal specialists were also viewed as familiar with LS and positioned to return positive screens. When they perform biopsies and order pathology tests, they are ultimately responsible for ensuring that cancer and LS screening results are returned, even if the ordering provider does not personally return the results. For example, if the gastrointestinal surgeon takes the tissue sample but does not feel comfortable returning results, then a provider with a relationship with the patient must do it.

"In my mind it would be the physician who removed the specimen...then that would just be part of the pathology report...If it comes back on the report we have a moral and legal responsibility to keep the patient informed." (P20, gastroenterologist)
"I don't know how comfortable surgeons are going to be at it...In which case the gastroenterologist needs to be ready to do it. They're the ones who are calling with the results. Otherwise, I think medical oncologists clearly have to be ready to do it." (P13, medical oncologist)

\section{Team-based return of results}

Despite the standard model of test ownership, and strong preferences for having a relationship with the patient before returning results, participants agreed that the individual returning screening results must have the appropriate expertise. LS is relatively rare, and so there is some lack of nuanced understanding of positive LS screen results. Some participants support an explicitly team-based approach, to ensure accurate, appropriate information for patients. In this case, the physician with the relationship with the patient can return results assisted by a genetic counselor who would offer necessary detailed knowledge.

"Probably the oncologist, but...a genetic counselor, in the room to help with interpretation and in the implications of those results." (P1, gastroenterologist)

“There's some multidisciplinary teams...they already have genetic counseling planned when the patient is returning for their oncology visit. They get their oncology to talk to you about their treatment and they get the genetic counseling talking about these results and the follow-up." (P18, pathologist)

In the absence of multidisciplinary teams or when an ordering physician is not comfortable returning results, several participants suggested a handoff to genetics would be warranted, and the ordering provider can bridge that connection to the additional provider.

"The oncologist might tell them, "This is your result and we'd like to send you to genetics to follow this up"... They're introducing the idea of a geneticist because they may not have seen genetics up until that point." (P17, clinical geneticist)

\section{Stage 3: providing patient follow-up}

The patient and family follow-up stage includes a more diffuse set of responsibilities. Participants across specialties agreed that whichever provider saw patients the most regularly after their cancer diagnosis could perform followup (e.g., an oncologist for those with long-term cancer treatment, or a primary care provider (PCP) for those without long-term cancer treatment), as follow-up for the patient may occur long after the cancer diagnosis.

"I think it's best for the person who's managing care to make that follow-up call. A pathologist...wouldn't 


\section{ORIGINAL RESEARCH ARTICLE}

necessarily have that connection to the rest of their care... I'd say it's part of the oncologist follow-up if it's somebody who has a tumor that's being screened, or I would say primary care if it is...from a family connection." (P9, primary care provider)

\section{Oncologists}

For some patients, the ongoing relationship may be with the oncologist leading their cancer treatment, often over several years, and may mean an oncologist is best-positioned to ensure follow-up.

\begin{abstract}
"The decision to go on from a positive screen test to getting definitive testing is really on ...the point person for that patient's cancer care. They're ultimately responsible for... communicating that result, and then communicating the importance of doing follow-up with the specialist to do definitive testing. If that still hasn't happened two years later, I think it could still be on whoever that patient is seeing as part of their cancer care follow-up." (P7, pathologist)
\end{abstract}

\section{Primary care providers}

It was widely acknowledged that patients undergoing cancer treatment are often not interested in the additional complexity around genetic testing for LS, or involving their at-risk relatives. In those cases, their PCP, if they have one, should ensure follow-up, as the PCP often has more familiarity with the patient than other providers. Despite current lack of knowledge about LS testing among PCPs, they could be educated to serve as a safeguard for follow-up that may be delayed or forgotten.

\footnotetext{
"Round about the diagnosis period...it's quite busy and dramatic, lots of things going on. Then, months go by... Chemotherapy's finished. The patient's...going through their periodic CT scan every year or six months...Then, it does get back into the primary care providers' list of things they have to feel responsible for." (P4, primary care provider)
}

"Often folks do have a good relationship with their primary...If they decline up front to do genetics and I can get any information back to their primary...I don't want the primary to think he or she has to do all of it, but I would be totally supportive of the primary saying, "This is a concern and I think you should...go see these genetics people..."” (P16, genetic counselor)

The PCP would also be the best person to coordinate longterm care for the patient, who, if positive for LS, needs cancer screenings beyond standard recommendations, and to support the patient reaching out to at-risk relatives, who may also need additional screening.
"I think having the primary care come in and play a major role...now implications of testing, both for the patient and the family are going to be important...not just for further colorectal cancers but other types of screening for other organs, also planning testing or screening earlier in the patient's family members." (P1, gastroenterologist)

\section{Medical geneticists or genetic counselors}

Although they lack ongoing relationships with patients, genetic specialists were also considered to be appropriately positioned for the follow-up role, given their expertise in interpreting genetic test results, and supporting family outreach.

"When we [medical genetics] get a positive result, we...talk about who they should notify in their family. We can help them draft a letter...that can go out to their family members...We have certainly seen huge extended families back...just to sit down and talk about... what the implications are and giving people resources so that they can go and get tested at their local geneticist." (P6, clinical geneticist)

One genetic counselor described the different motivations of clinicians and counselors.

"Docs are focused on patients, docs aren't focused on families... They may not always realize this has implications for other people... The physician isn't going to have a relationship with anybody else in the family...[or] feel the same obligation to go seek them out." (P16, genetic counselor)

By contrast, particularly in rural areas, and depending on the health-care system, the PCP might be positioned to guide patients in family outreach efforts. However, there are potential legal barriers to doing so.

“...especially in nonurban settings, where...you're talking now about maybe a practice has a half dozen people, they may be one of two practices in this town or a small city, so it's very likely that other family members will be going to that provider. That provider now has incentive to get the whole family tested but might not be able to discuss it because of our crazy health-care system." (P18, pathologist)

\section{Comparison across stakeholders}

No participant felt all three stages should be owned by a single provider or specialty, as all acknowledged complexity in how patients are seen in the medical system. All participants felt that more than one specialty could be appropriate to perform each task, and there were no clear patterns between participant specialty and perceived appropriate specialty owner. Table 5 summarizes the number of times participants endorsed particular specialties as owners of each stage. 
Table 5 Specialty making the suggestion for task ownership (left-hand column) by times a particular "owner" was suggested (table body)

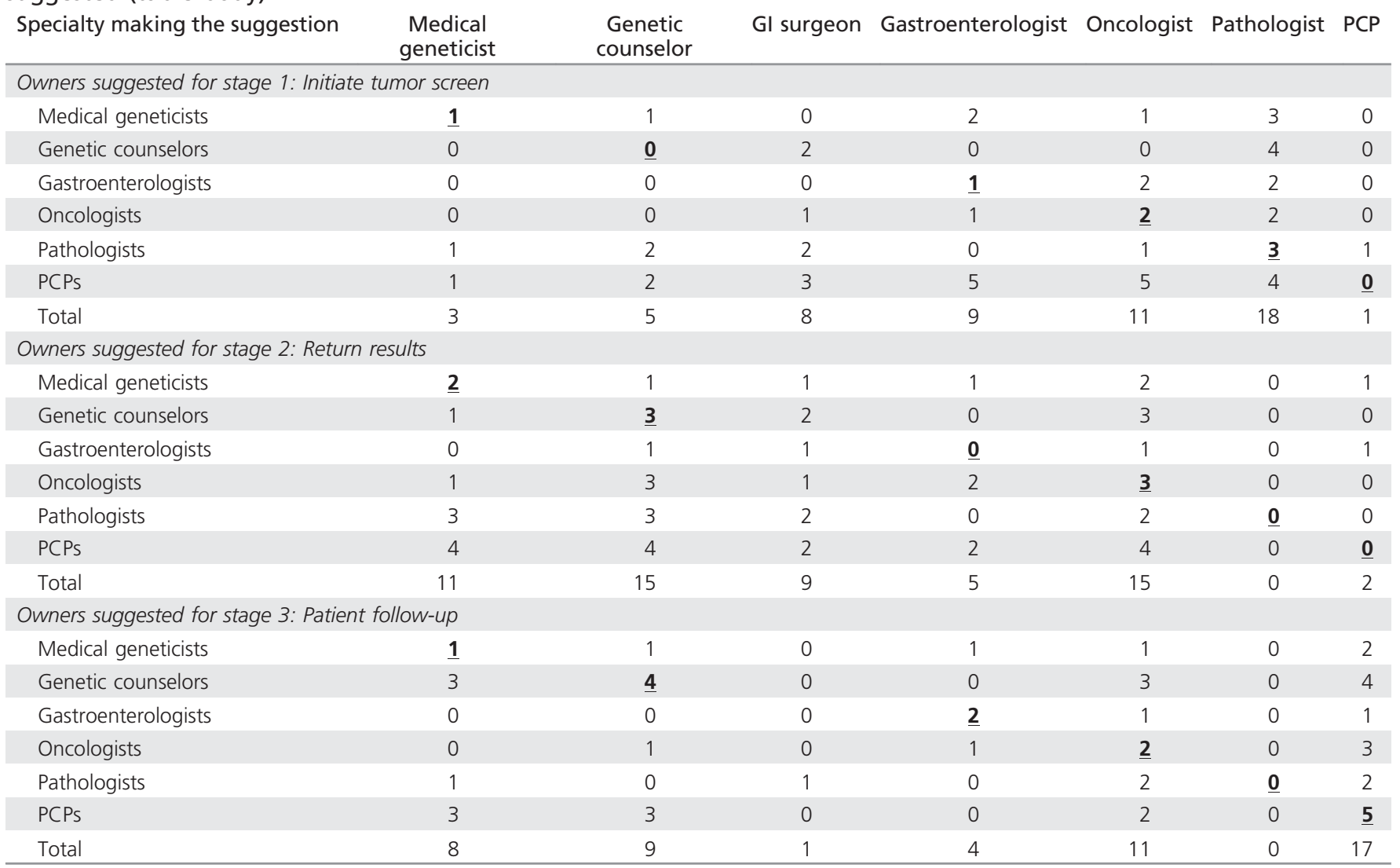

$\mathrm{Gl}$, gastrointestinal; $\mathrm{PCP}$, primary care provider.

Numbers bolded and underlined indicate the number of a given specialty who felt their specialty could own the stage. Participants were not limited to one choice for each stage, so total numbers exceed the total number in our sample $(n=20)$.

\section{DISCUSSION}

We asked specialists with a role in UTS, in a range of clinical settings, to identify which specialties could own each stage of UTS implementation and why. This approach revealed that often "role" and "specialty" are conflated but, in reality, similar roles might be filled by several specialties. Our findings are meaningful for a number of areas of health-care delivery research, namely, implementation science, patient safety, the patient-centered medical home, and telehealth activities.

Our data demonstrate that clinicians recognize ambiguity in task ownership, which is not proscriptively assigned across a clinical pathway in most clinical practice guidelines. Rather, assigning ownership of steps in a multistep intervention is left to the implementing institution or provider group to determine. A recent study exploring UTS implementation barriers and facilitators identified ownership of tasks as a key gap to widespread implementation. ${ }^{8}$ Despite consensus in the implementation science literature on the importance of site "champions,"15-17 the literature lacks specific guidance on identifying and engaging key stakeholders and defining their roles. ${ }^{18}$ Our data suggest that flexible guidance, proposing several specialties capable of owning each task, in implementation science projects and clinical practice guidelines would help inform genomic medicine implementation across diverse settings. Flexible guidance could support lower-resourced clinics in meeting the same service goals for their patient populations as more highly resourced settings.

Unlike the implementation science literature, patient safety researchers have long investigated issues of ownership, notably in patient handoffs when the care team changes, ${ }^{19}$ interprofessional role misunderstandings in various settings, ${ }^{20,21}$ and issues related to "chain-of-command." 22 Our data demonstrate that the deployment of UTS for LS can be viewed as a series of handoffs along a clinical pathway. Lessons from patient safety research show that paying attention to why and when a task is done, and which prompts help to ensure task completion, can inform successful handoffs. Previous studies on screen-positive patient uptake of germ-line testing in UTS complement the patient safety literature by showing that a defining difference between institutions with high- and low-patient follow-up is having genetic counselors play a central role in facilitating and ensuring handoffs. ${ }^{9,23}$ 
The patient-centered medical home (PCMH) model may offer insights, when multiple providers are involved in a patient's care, as clearly exists in UTS implementation. PCMH leverages primary care's strength in providing preventive services while also increasing access to services for comprehensive and continuous, rather than episodic, care. ${ }^{24}$ Our participants recognized the health-care provider with the strongest relationship with the patient as best suited to owning the follow-up stage, which could be the oncologist, but also the PCP. The PCMH model, applied across variously resourced settings, has resulted in increased cancer screening rates across all socioeconomic status contexts and a reduction in disparities between highest and lowest socioeconomic status when compared to non-PCMH practices. ${ }^{24}$ Primary care also has been recognized as essential for integrating genomic medicine into clinical care through the PCMH mechanism. ${ }^{25}$ This suggests that application of the PCMH model to UTS should be explored in the context of meeting Healthy People 2020 goals $^{7}$ and preventing genomic medicine from increasing care disparities across socioeconomic status. ${ }^{12,26}$

Providing specialty support to clinicians and patients in remote settings is already being explored, notably through telehealth/telegenetics (i.e., distance consultations via video conference). A recent study showed that early stage chronic obstructive pulmonary disease patients enthusiastically supported telehealth as a supplemental means for care delivery. ${ }^{27}$ Studies are needed to determine if patients receiving genetic counseling using telegenetics would agree. Although a potentially promising method to deliver support for genomic medicine, telehealth, as an intervention, needs implementation studies. ${ }^{28}$

In addition to telehealth, group counseling and nonspecialist counseling have become increasingly common with the rise of cancer genetic practice and the limited number of genetic counselors in the United States. While most study participants agreed that genetic counselors are ideal providers in UTS, they recognized that the availability of genetic counselors is too limited for widespread implementation of clinical genetic services and access to them is distributed inequitably. ${ }^{29-31}$ Our results advance the possibility that some components of genomic medicine can be delivered by clinicians who are not genetic specialists, as suggested elsewhere. ${ }^{9}$ However, comparative effectiveness research is needed to evaluate these options. ${ }^{32,33}$ Other support might include increased genomics education in medical school, ${ }^{34,35}$ continuing education, the use of templates, and just-in-time resources for providers, such as a well-designed clinical decision support tool. ${ }^{35}$ Such support is crucial for PCPs to be involved in UTS-even if mainly focused on follow-up and prevention (e.g., the PCMH model). If UTS is to be successfully implemented across health-care settings, some PCPs will have to be involved.

This study has two main limitations. Although gastrointestinal surgeons could play an important role in UTS for LS, no such specialists were available for the study, and any unique perspectives they might hold are not included in this analysis. Second, as an exploratory study, generalizability of these findings is unknown, since only site-specific tailoring can provide definitive guidance for UTS task ownership. Unexplored implementation challenges remain, including which resources would drive decisions about ownership in a given health-care setting. However, our data provide a foundation for exploring these issues in a systematic fashion while encouraging clinic personnel and providers to think beyond the conflation of "role" and "specialty" when implementing UTS. Next steps include establishing tailored UTS protocols in lower-resourced settings and exploring patient and clinician experiences of LS screening in the absence of genetic specialists, possibly using telegenetics or nonspecialist consultation modes.

Participants regarded UTS for LS as attainable across various health-care settings. Successful implementation will require the reduction of current barriers including identifying clinical specialty ownership of each stage. Our data offer insights into the procedural requirements for LS screening, with a menu of options for potential specialties, and descriptions of key tasks and examples of workflow relevant to each stage. Awareness of these tasks can inform tailoring of UTS implementation to the needs of individual clinics and health-care systems-even in the absence of a genetic specialist-with appropriate clinician support. Unlike many genetic tests that still require a stronger evidence base, assessments of clinical and cost effectiveness, and implementation and evaluation studies, ${ }^{34}$ UTS for LS provides an exemplar of genomic medicine that is ready for primetime. ${ }^{36}$ Determining resource needs and devising ways to meet them can help expand the benefits of genomic medicine beyond heavily resourced health systems. Procedural barriers should not impede universal access to genomic medicine.

\section{ACKNOWLEDGMENTS}

We owe special thanks to the study participants.

The content is solely the responsibility of the authors and does not necessarily represent the official views of the National Institutes of Health or the authors' affiliated institution.

\section{DISCLOSURE}

Support for this research comes from National Human Genome Research Institute grant K01 HG008180 (D.K.). The authors declare no other conflicts of interest.

\section{REFERENCES}

1. Hampel H, Frankel WL, Martin E, et al. Feasibility of screening for Lynch syndrome among patients with colorectal cancer. J Clin Oncol 2008;26: 5783-5788.

2. Lindor NM, Petersen GM, Hadley DW, et al. Recommendations for the care of individuals with an inherited predisposition to Lynch syndrome: a systematic review. JAMA 2006;296:1507-1517.

3. Berg $A O$, for the Evaluation of Genomic Applications in Practice and Prevention (EGAPP) Working Group. Recommendations from the EGAPP Working Group: genetic testing strategies in newly diagnosed individuals with colorectal cancer aimed at reducing morbidity and mortality from Lynch syndrome in relatives. Genet Med 2009;11:35-41. 
4. Bellcross CA, Bedrosian SR, Daniels E, et al. Implementing screening for Lynch syndrome among patients with newly diagnosed colorectal cancer: summary of a public health/clinical collaborative meeting. Genet Med 2012;14:152-162.

5. Cross DS, Rahm AK, Kauffman TL, et al. Underutilization of Lynch syndrome screening in a multisite study of patients with colorectal cancer. Genet Med 2013;15:933-940.

6. Hampel H. NCCN increases the emphasis on genetic/familial high-risk assessment in colorectal cancer. J Natl Compr Canc Netw 2014;12(suppl 5): 829-831.

7. Office of Disease Prevention and Health Promotion Healthy People 2020 Topics \& Objectives: Genomics https://www.healthypeople.gov/2020/ topics-objectives/topic/genomics/objectives. Accessed 25 July 2016.

8. Schneider JL, Davis J, Kauffman TL, et al. Stakeholder perspectives on implementing a universal Lynch syndrome screening program: a qualitative study of early barriers and facilitators. Genet Med 2016;18: 152-161.

9. Heald B, Plesec T, Liu $X$, et al. Implementation of universal microsatellite instability and immunohistochemistry screening for diagnosing Lynch syndrome in a large academic medical center. J Clin Oncol 2013;31: 1336-1340.

10. Patton MQ, Patton MQ. Qualitative Research and Evaluation Methods. Sage Publications: Thousand Oaks, CA, 2002.

11. Hsieh HF, Shannon SE. Three approaches to qualitative content analysis. Qual Health Res 2005;15:1277-1288.

12. Vaismoradi $M$, Turunen $H$, Bondas $T$. Content analysis and thematic analysis: implications for conducting a qualitative descriptive study. Nurs Health Sci 2013;15:398-405.

13. National Coalition for Health Professional Education in Genetics Colorectal cancer fact sheets: testing for Lynch syndrome 2012. http://www.nchpeg.org/documents/crc/11-0456\%20Fact\%20sheets\%20 (Risk\%20assessment\%20).pdf. Accessed 4/20/17.

14. Cohen SA. Current Lynch syndrome tumor screening practices: a survey of genetic counselors. J Genet Couns 2014;23:38-47.

15. Jenkins J, Calzone KA, Caskey S, et al. Methods of genomic competency integration in practice. J Nurs Scholarsh 2015;47:200-210.

16. Bauer MS, Damschroder L, Hagedorn $H$, et al. An introduction to implementation science for the non-specialist. BMC Psychol 2015;3:32.

17. Birken SA, Lee SY, Weiner BJ, et al. From strategy to action: how top managers' support increases middle managers' commitment to innovation implementation in health care organizations. Health Care Manage Rev 2015;40:159-168.

18. Damschroder LJ, Aron DC, Keith RE, et al. Fostering implementation of health services research findings into practice: a consolidated framework for advancing implementation science. Implement Sci 2009;4:50.

19. Lee SH, Phan PH, Dorman T, et al. Handoffs, safety culture, and practices: evidence from the hospital survey on patient safety culture. BMC Health Serv Res 2016;16:254.
20. Steinemann S, Kurosawa G, Wei A, et al. Role confusion and selfassessment in interprofessional trauma teams. Am J Surg 2016;211: 482-488.

21. Stocker M, Pilgrim SB, Burmester $M$, et al. Interprofessional team management in pediatric critical care: some challenges and possible solutions. J Multidiscip Healthc 2016;9:47-58.

22. McGinty MD, Burke TA, Barnett DJ, et al. Hospital evacuation and shelterin-place: who is responsible for decision-making? Disaster Med Public Health Prep 2016;10:320-324.

23. Cragun D, DeBate RD, Vadaparampil ST, et al. Comparing universal Lynch syndrome tumor-screening programs to evaluate associations between implementation strategies and patient follow-through. Genet Med 2014;16:773-782.

24. Markovitz AR, Alexander JA, Lantz PM, et al. Patient-centered medical home implementation and use of preventive services: the role of practice socioeconomic context. JAMA Intern Med 2015;175:598-606.

25. David SP, Johnson SG, Berger AC, et al. Making personalized health care even more personalized: insights from activities of the IOM Genomics Roundtable. Ann Fam Med 2015;13:373-380.

26. Suther S, Kiros GE. Barriers to the use of genetic testing: a study of racial and ethnic disparities. Genet Med 2009;11:655-662.

27. Fitzsimmons DA, Thompson J, Bentley CL, et al. Comparison of patient perceptions of telehealth-supported and specialist nursing interventions for early stage COPD: a qualitative study. BMC Health Serv Res 2016;16: 420.

28. Taylor J, Coates E, Wessels B, et al. Implementing solutions to improve and expand telehealth adoption: participatory action research in four community healthcare settings. BMC Health Serv Res 2015:15:529.

29. Hawkins AK, Hayden MR. A grand challenge: providing benefits of clinical genetics to those in need. Genet Med 2011;13:197-200.

30. Wicklund C. Genetics Education Pipeline and Workforce. National Society of Genetic Counselors, 2008

31. Roche MI, Greb AE. It's time to ramp up genetic counseling training. Genet Med 2016;18:768-769.

32. Buchanan AH, Rahm AK, Williams JL. Alternate service delivery models in cancer genetic counseling: a mini-review. Front Oncol 2016;6:120.

33. Cohen SA, Marvin ML, Riley BD, et al. Identification of genetic counseling service delivery models in practice: a report from the NSGC Service Delivery Model Task Force. J Genet Couns 2013;22:411-421.

34. National Academies of Sciences, Engineering, and Medicine. Applying an Implementation Science Approach to Genomic Medicine: Workshop Summary. National Academies Press: Washington DC, 2016.

35. US Department of Health and Human Services Genetics education and training: report of the Secretary's Advisory Committee on Genetics, Health, and Society. Washington, DC 2011.

36. Mange S, Bellcross C, Cragun D, et al. Creation of a network to promote universal screening for Lynch syndrome: the Lynch Syndrome Screening Network. J Genet Couns 2015:24:421-427. 